\title{
Clinicopathologic characteristics and surgical outcome of synthetic fiber conjunctival granuloma
}

\author{
Zhang Chen ${ }^{1}$, Tianyang Wang ${ }^{2}$, Qintuo Pan ${ }^{1}$, Zhaoliang Zhang ${ }^{1}$ (D) and Zongduan Zhang ${ }^{\text {** }}$
}

\begin{abstract}
Background: Until recently, synthetic fiber conjunctival granuloma (SFCG) is rarely reported and has been poorly understood. Our study was to explore the clinical features, histopathologic characteristics, surgical outcomes, and prognosis of SFCG after surgical excision.

Methods: Retrospective review of clinical findings, histopathological and immunohistochemical studies identified 18 cases of SFCG. Specimens were routinely processed and stained with H\&E. Immunohistochemical stains for GMS, PAS, CD68 and CK-pan were also performed.

Results: Eighteen patients with an average age of $9.3 \pm 6.6$ years had a tender white to red mass on the conjunctiva. All the lesions were completely removed, and none of the patients relapsed. Histologically, all of the specimens revealed inflammatory granulation tissues with a large number of inflammatory cells infiltration and the presence of synthetic fibers. Immunohistochemical stains were positive for CD68, CK, GMS and PAS.

Conclusions: Synthetic fiber conjunctival granuloma is an uncommon lesion with foreign body sensation caused by inoculation of synthetic exogenous materials. These lesions are mostly unilateral and occur in the inferior conjunctival fornix. SFCGs are characterized by a large number of inflammatory cells infiltration and the presence of synthetic fibers. Surgical excision followed by topical corticosteroids has been clinically proven to be effective.
\end{abstract}

Keywords: Synthetic fiber conjunctival granuloma, Clinical feature, Histopathologic

\section{Background}

Many non-synthetic and synthetic exogenous materials may play a vital role in causing foreign body conjunctival granulomas. To date, several studies have indicated synthetic fiber as a possible cause of conjunctival granuloma in children [1-3]. It is sometimes called "teddy bear" granuloma because some cases were caused by the materials used to produce stuffed animals [4]. It is also a rare granulomatous foreign body reaction of the conjunctiva [5]. The eye's protective mechanism of blinking and tearing

\footnotetext{
* Correspondence: zzduan@163.com

'Wenzhou Medical University Eye Hospital, 270 Xueyuan Road, Wenzhou 325027, Zhejiang, China

Full list of author information is available at the end of the article
}

usually removes foreign bodies from the ocular surface. However, a research has reported that children were more tolerant to ocular irritation caused by foreign bodies, and foreign bodies may occasionally embed in the underlying stroma and be encapsulated by the mucous [6]. Retaining these materials may initiate a local chronic inflammatory response that cause lesions [4]. Synthetic fiber conjunctival granuloma (SFCG) is relatively rare. It is usually unilateral and located in the inferior conjunctival fornix. The patients usually have no history of trauma and are asymptomatic [5]. All of the lesions in our case series were excised surgically and sent for histopathological analysis. Microscopic examination revealed that the conjunctival granuloma was composed of granulation tissue with chronic inflammation 
and foreign body aggregates consistent with synthetic fibers. To date, very little research has been conducted on SFCG, and most studies have had small sample sizes. Thus, the clinical and histopathologic characteristics and treatment outcomes of the disease remain poorly understood. The present research with the largest case series of 18 patients aims to facilitate further understanding of the disease(An additional file shows this in more detail (see Additional file 1)).

\section{Methods}

We retrospectively evaluated 18 patients who underwent surgical excision of SFCG between July 2011 and June 2019 at the Wenzhou Medical University Eye Hospital (Table 1). The primary selection criteria for the 18 patients was histologically proven SFCG. The medical records including the patients' age and sex, clinical presentation, duration of signs and symptoms, location of mass, treatment modalities, and outcomes were retrospectively reviewed (Table 1). We also gathered clinical photographs obtained on eversion of the inferior eyelids and intraoperative findings of the patients. All of the patients underwent surgical excision by the same ophthalmologist. All of the conjunctival granulomas were excised completely under surface anesthesia except for one patient who underwent general anesthesia, followed by the administration of topical corticosteroid eye drops for 1 week. All of the surgical specimens were grossly examined for size and color. Specimens from each case were routinely stained with hematoxylin and eosin, GMS and PAS. Immunohistochemical stains for CD68 and CK-pan were also performed. Mouse monoclonal antibodies against human CK-pan and CD68 and MaxVision $^{\text {Tw/ }} /$ HRP against mouse and rabbit were used in these tests. All of the 18 patients were otherwise healthy apart from the disease, with no history of surgery or ocular trauma. The study was approved by the Ethics Committee of the Wenzhou Medical University Eye Hospital (approval number:2020-163-K-148).

\section{Results}

A total of 18 patients with SFCG were included in this study. Males constituted 38.9\% (7/18) and females $61.1 \%$ $(11 / 18)$. The patients ages ranged from 3 to 31 years (9.3 \pm 6.6 years). Among the patients' granulomas, 2 masses were located in the inferior palpebral conjunctiva and 15 masses were located in the inferior fornix (Fig. 1a). Only one mass was located in the left upper eyelid (Fig. 1b). The unilateral eye was involved in all of the patients. The right eye was involved in $55.6 \%(10 / 18)$ and the left eye was involved in $44.4 \%$ (8/18). We collected all of the patients' medical records. No previous history of cutaneous lesions or trauma was noted. Physical and ocular examinations revealed normal findings except for a soft, non-tender mass in the conjunctiva.

Essential information and clinical features of the 18 patients are summarized in Table 1. All of the patients reported foreign body sensation from 1 week up to 24 months prior to treatment. Other common symptoms

Table 1 Demographic and clinical features of 18 patients with synthetic fiber conjunctival granulomas

\begin{tabular}{|c|c|c|c|c|c|c|}
\hline Patient no. & Age range at last review, $y$ & Duration & Location & Size, $\mathrm{mm}$ & Color & Symptoms \\
\hline 1 & $6 \sim 10$ & $2 w k$ & RLL & $1 \times 2$ & White & FBS \\
\hline 2 & $1 \sim 5$ & $1 y$ & LLL & $10 \times 5$ & Red-white & Lump, FBS \\
\hline 3 & $1 \sim 5$ & $6 \mathrm{mo}$ & RLL & $7 \times 6$ & White & Lump, FBS \\
\hline 4 & $6 \sim 10$ & $1 y$ & LLL & $10 \times 2$ & Red-white & Lump, FBS \\
\hline 5 & $6 \sim 10$ & $2 w k$ & RLL & $3 \times 8$ & Red-white & Lump, FBS, slight pain \\
\hline 6 & $16 \sim 20$ & $1 y$ & RLL & $4 \times 1$ & Yellow-white & FBS \\
\hline 7 & $6 \sim 10$ & 1 wk & RLL & $3 \times 2$ & Red-white & FBS \\
\hline 8 & $6 \sim 10$ & $2 w k$ & LLL & $4 \times 6$ & Red & Lump, FBS \\
\hline 9 & $6 \sim 10$ & $1 \mathrm{mo}$ & LLL & $2 \times 3$ & Red & FBS, discharge \\
\hline 10 & $6 \sim 10$ & $2 w k$ & RLL & $3 \times 6$ & White & FBS, itching, discharge \\
\hline 11 & $1 \sim 5$ & $2 w k$ & LUL & $2 \times 7$ & White & Lump, FBS, discharge \\
\hline 12 & $16 \sim 20$ & $1 \mathrm{wk}$ & LLL & $5 \times 4$ & Red & FBS, slight pain, itching \\
\hline 13 & $21 \sim$ & $6 \mathrm{mo}$ & RLL & $2 \times 4$ & Red-white & FBS, itching \\
\hline 14 & $1 \sim 5$ & $2 \mathrm{mo}$ & RLL & $3 \times 6$ & Red & FBS \\
\hline 15 & $6 \sim 10$ & 3 wk & LLL & $2 \times 5$ & Red & FBS, slight pain, discharge \\
\hline 16 & $6 \sim 10$ & $7 \mathrm{mo}$ & RLL & $3 \times 5$ & Red-white & FBS \\
\hline 17 & $6 \sim 10$ & 1 wk & LLL & $5 \times 7$ & White & Lump, FBS \\
\hline 18 & $11 \sim 15$ & $1 \mathrm{mo}$ & RLL & $4 \times 6$ & Red-white & FBS, itching \\
\hline
\end{tabular}

LLL Left lower lid, LUL Left upper lid, RLL Right lower lid, FBS Foreign body sensation, mo months, $y$ years, wk weeks, $F$ Female, $M$ Male 


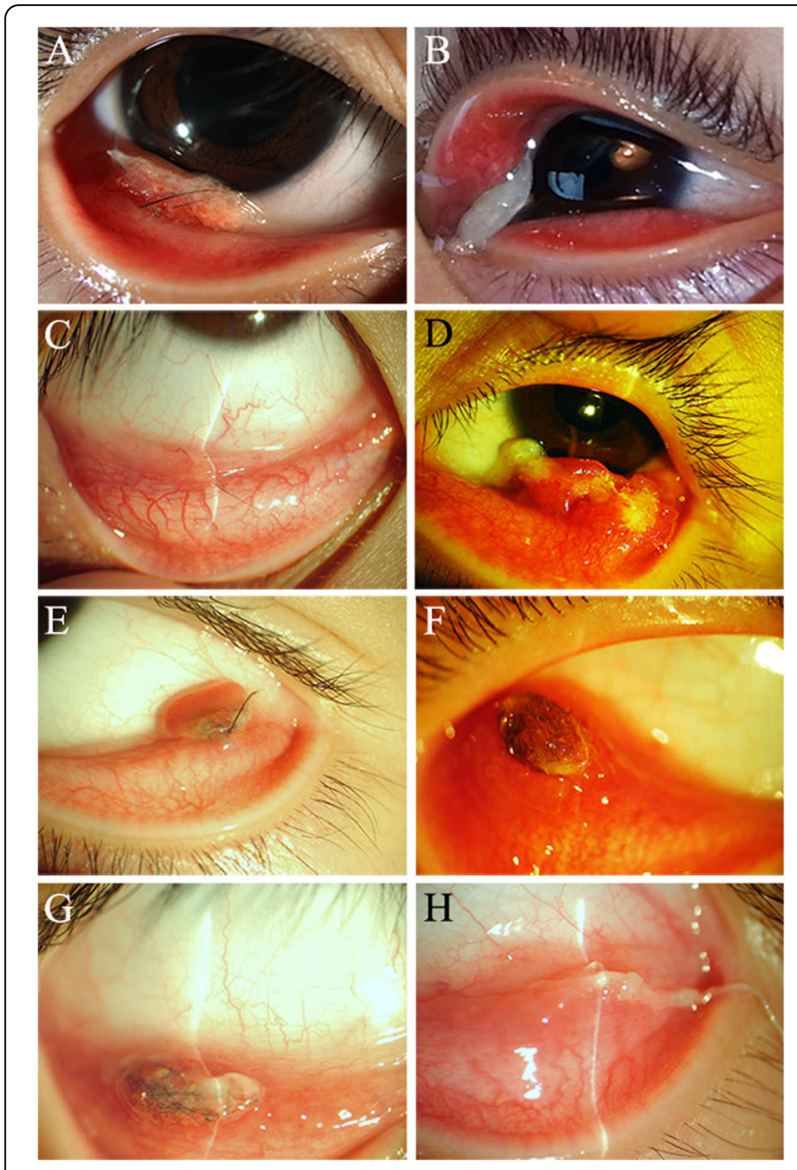

Fig. 1 Different locations, sizes, and shapes of synthetic fiber conjunctival granulomas. a A granuloma present on the lower eyelid. b Conjunctival lesion located on the upper eyelid. c The smallest conjunctival granuloma seen in the inferior eyelid fornix of the right eye measuring $1 \times 2 \mathrm{~mm}$. $\mathbf{d}$ The largest lesion seen in the inferior eyelid fornix of the left eye measuring $5 \times 10 \mathrm{~mm}$. e-h Photographs show the various shapes of the lesions, such as round, oval, fabiform, or other irregular forms

included slight pain (3/18), itching (4/18), and eye discharge (4/18). The color and size of the conjunctival granulomas caused by synthetics fiber varied. These nodules ranged from $1 \times 2 \mathrm{~mm}$ to $5 \times 10 \mathrm{~mm}$ in size (Fig. $1 \mathrm{c}$ and d) and white to red in color. They appeared solid or cystic and did not adhere to the surrounding tissues (Table 1). The shapes of the granulomas were round, oval, fabiform, or other irregular forms. The most common shape was oval (Fig. 1e-h). Clinical examination revealed the lesions were non-palpable or discernible externally in most patients. Upon eversion of the eyelids, an elevated, well-defined, solitary nodule was found beneath the transparent palpebral conjunctiva with various synthetic fibers. The adjacent tissue was not inflamed or incrassated. External morphologies of the eyelashes were normal in all of the cases, and distichiasis, trichiasis, or ectopic cilia were not observed.
Microscopic examination revealed a proliferation of inflammatory granulation tissue with many inflammatory cells including lymphocytes, plasma cells, eosinophils and neutrophils (Fig. 2a). Refractile foreign fibers were noted in edematous connective tissue containing neutrophils, foreign body giant cells and multinucleated histiocytes (Fig. 2b). Synthetic fibers were identified by their relatively uniform size, and some fibers exhibited central black granules (Fig. 2c and d). Most of the photomicrographs in our cases had similar pathological findings; however, case 2 had different sized mammillaryshaped red-white foreign bodies. Histological examination also revealed an inflammatory process in the substantia propria covered by conjunctival epithelium. Interestingly, we found some rhombic, pink substances (Fig. 2e) and a ring-like double spindle, translucent substance (Fig. 2f) that was not confirmed. Differential diagnoses should include non-infectious, immune, and infection-mediated conjunctival granulomas from the point of histopathology. Immunohistochemistry demonstrated that the goblet cells were positive for GMS stain and PAS stain (Fig. 3a and b) and the macrophages were positive for CD68 (Fig. 3c). The evaluation also showed positive staining with CK-pan (Fig. 3d). Most GMS stains, PAS stains, CK-pan and CD68 -positive cells were around the synthetic fibers of the granulation tissues.

Management modalities included surgical excision of the granulomas (Fig. 4a-c) and the administration of topical corticosteroid eye drops. The lesions completely resolved. Only 1 patient in the sample $(5.6 \%)$ underwent general anesthesia due to his young age and anxiety, and the rest (94.4\%) underwent topical anesthesia. All of the lesions completely resolved after treatment. During a mean followup period of 12 months (range, 8-20 months), none of patients showed significant recurrence or foreign body sensation after surgical debulking. There was no abnormality in their conjunctivas and corneas (Fig. 4d).

\section{Discussion}

This study presents the largest series of patients with SFCG, improving the medical record data regarding this disease. The granuloma is a result of chronic inflammatory reaction. Synthetic fibers and hair exhibit good histocompatibility. Therefore, they will induce local chronic inflammation that is different from acute inflammatory reaction caused by bacteria when they embed in the underlying stroma and are encapsulated by mucous. Local chronic inflammation is usually asymptomatic. In addition, the mass mainly occurs in the inferior eyelid fornix [5]. Thus, patients rarely have ocular irritation symptoms, it is not easy to identify, and is often an occasional finding.

Prior studies have demonstrated a strong relationship between the lesions and various other objects containing synthetic fibers, including pullover sweaters, bedding, 

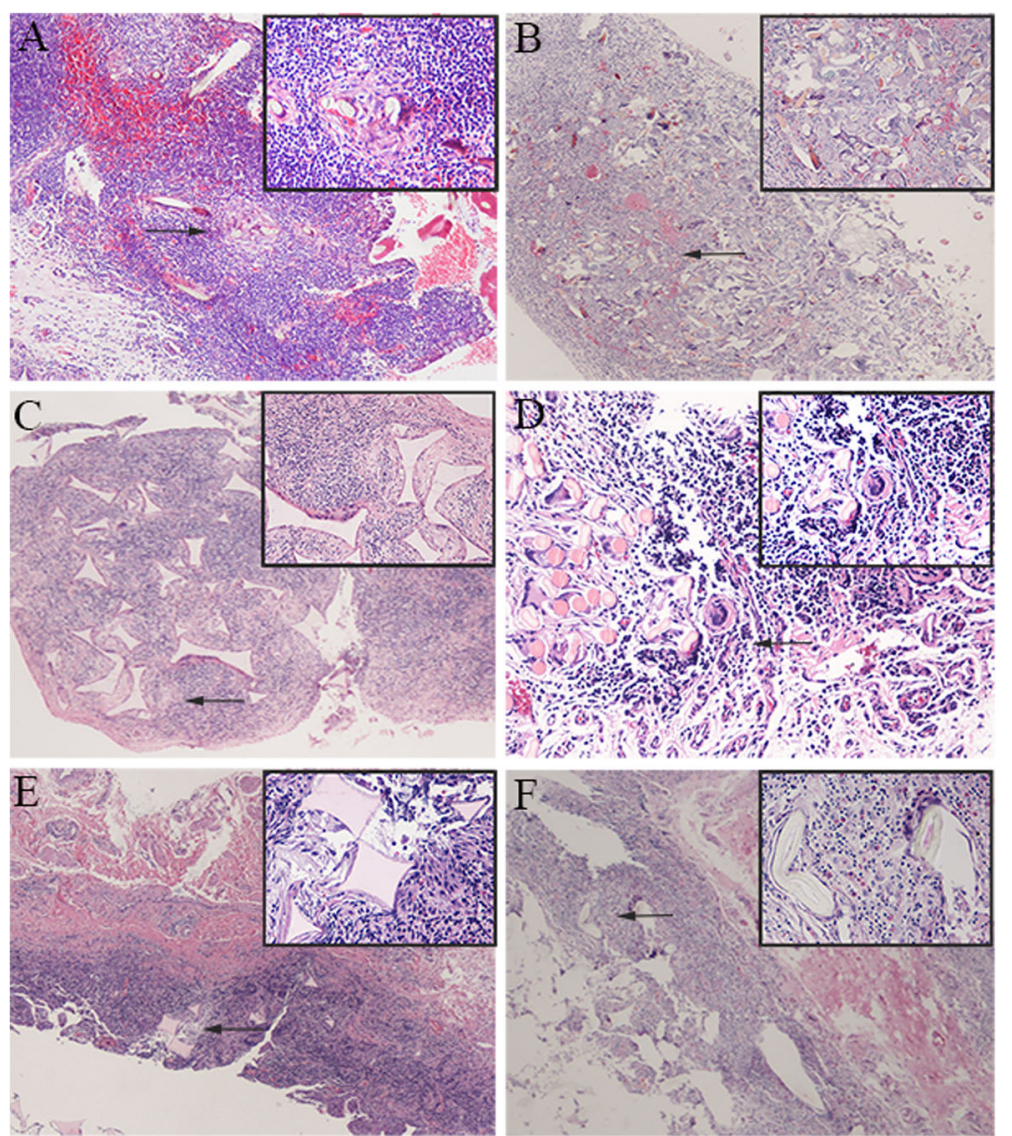

Fig. 2 Histopathologic findings. a Photomicrograph showing the proliferation of granulation tissue with a large amount of inflammatory cell infiltration (hematoxylin-eosin, $\times 100$; insets $\times 400$ ). b Refractile foreign fibers noted in edematous connective tissue containing inflammatory cells (hematoxylin-eosin, $\times 40$; insets $\times 400$ ). c-d Synthetic fibers with relatively uniform size or central black granules (c hematoxylin-eosin, $\times 40$; insets $\times 200$. $\mathbf{d}$ hematoxylin-eosin, $\times 200$; insets $\times 400$ ). e The synthetic fibers are rhombic, pink, and surrounded by histiocytic giant cells (hematoxylin-eosin, $\times 40$; insets $\times 400$ ). $\mathbf{f}$ The synthetic fibers are pink, double spindle, translucent, and surrounded by histiocytic giant cells (hematoxylin-eosin, $\times 40$; insets $\times 400$ )

and blankets $[3,4,7]$. In our study, the etiology was identical to prior reports. Therefore, we believe avoiding close exposure to potential primary sources of synthetic fibers is crucial for preventing inflammatory granuloma growth.

SFCG was first reported by Weinberg et al. (1984) in a case series of 5 patients [1]. To date, 20 additional patients with conjunctival foreign body granulomas caused by synthetic fibers have been reported (PubMed database research, Table 2). As reported in these cases, the lesions were usually unilateral and mainly in the inferior fornix [3]. Compared to adolescents, children usually have a higher incidence of granulomas because they are more likely to be exposed to stuffed animals [8]. The ages of patients in the published cases ranged from 26 months to 17 years old [1, $2]$. Based on the reviewed literature, including ours, the most common clinical symptom of SFCG is longstanding foreign body sensation; however, the majority of patients most often neglect the symptoms, which typically were present from many weeks up to a few months after exposure $[3,6,7,9]$. Patients are usually referred to the hospital because of an occasional finding of a mass in the eye. It is usually recognized weeks or months after lesion formation. Of all the cases, only one patient reported by Farooq et al. presented with ocular irritation in her left eye [10]. They found the girl had developed severe keratitis and corneal ulceration. In our case series, in addition to foreign body sensations, other symptoms or signs including lumps and slight pain have been reported, and no other discomfort or ocular symptoms were demonstrated.

Schmack et al. reported that the presence of a unilateral inferior conjunctival mass was the most reliable clinical sign indicating SFCG [4]. In contrast to clinical signs, the histologic features of SFCG are much more characteristic and diagnostic. Synthetic fibers can be confirmed by their relatively uniform size, strong birefringence under polarized light, and black granular spots. The characteristic histological features of large amounts of inflammatory cells including lymphocytes, plasma cells, eosinophils, and neutrophils presenting around the fibers supported the 

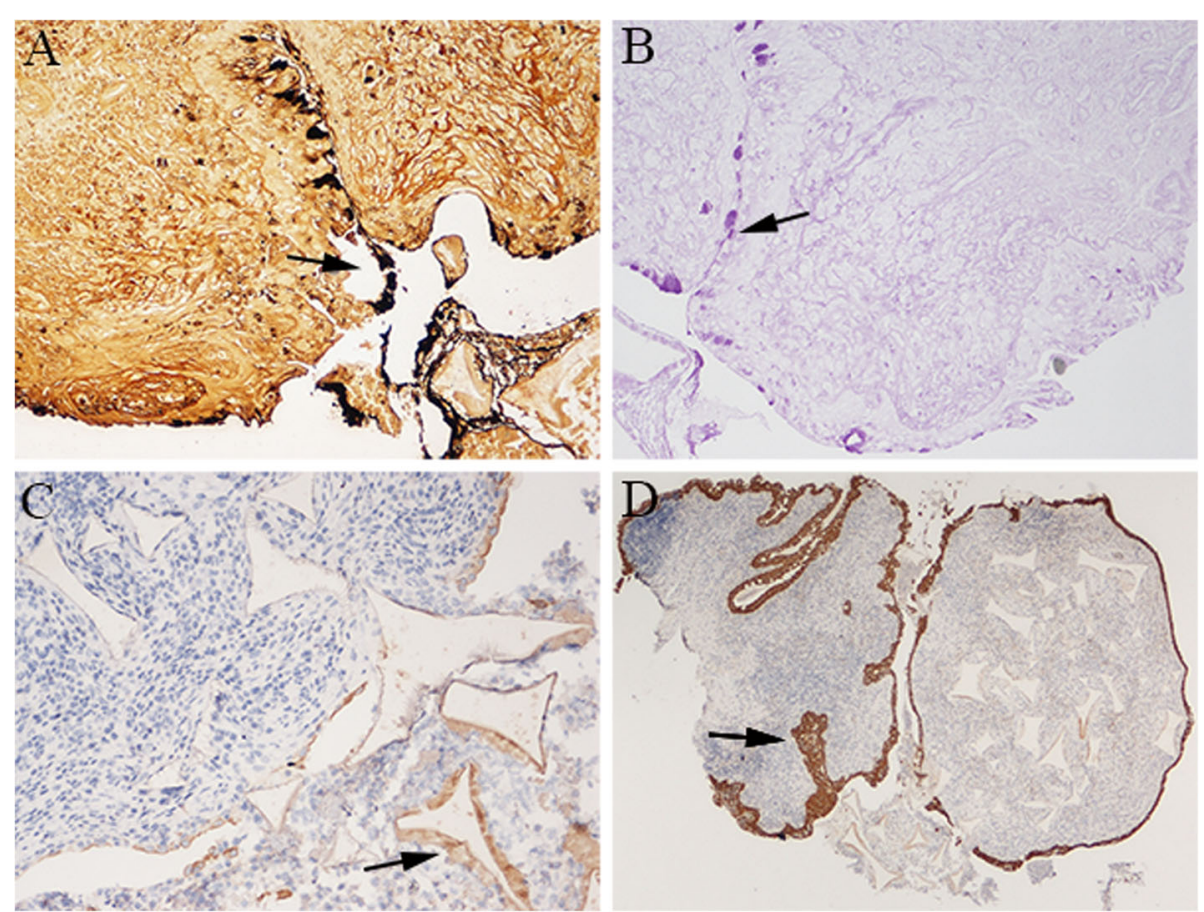

Fig. 3 Immunohistochemical results. a GMS stain-positive goblet cells (magnification $\times 200)$. b PAS stain-positive goblet cells (magnification $\times$ 200). c CD68-positive macrophages (magnification $\times 200$ ). d CK-pan positive conjunctival epithelial cells (magnification $\times 40$ )
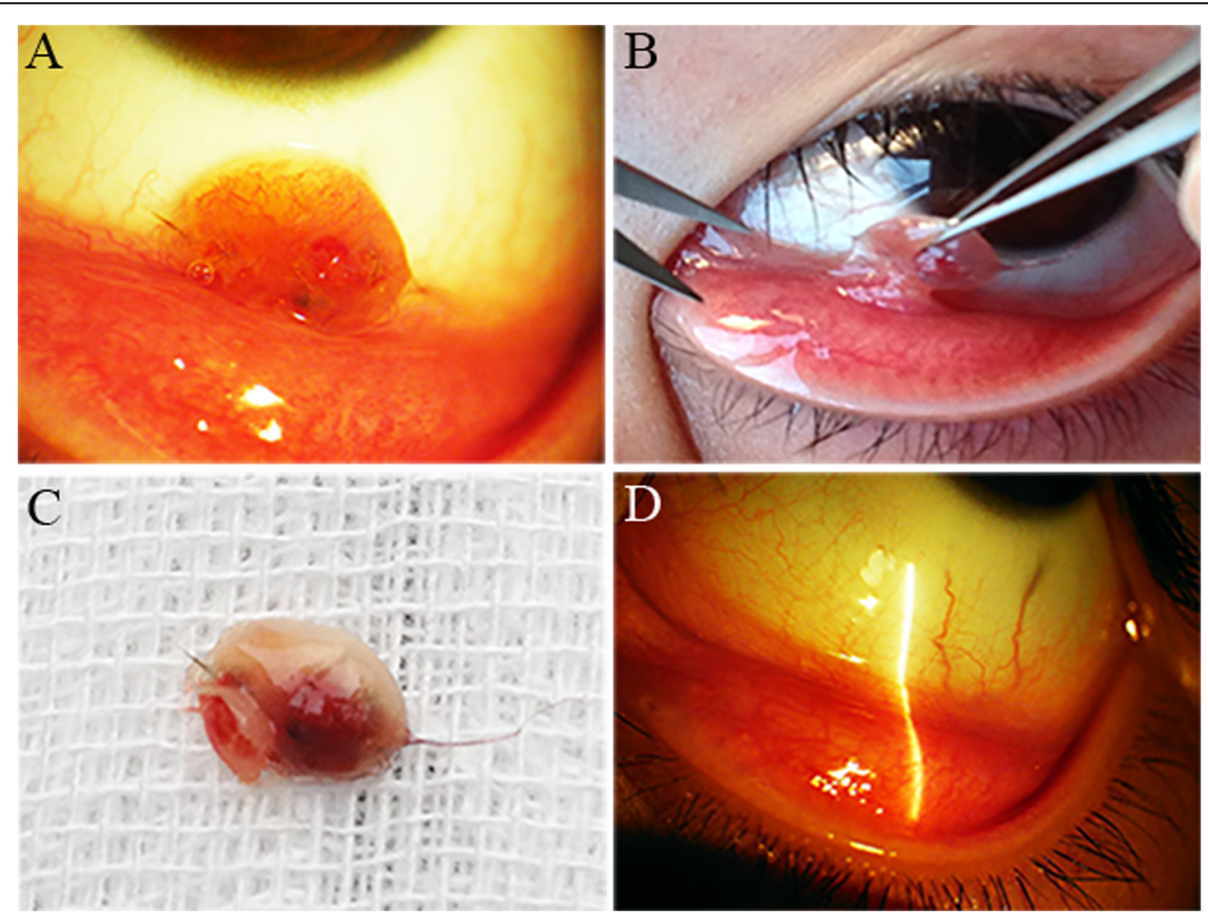

Fig. 4 The surgical procedure of removing synthetic fiber conjunctival granulomas. $\mathbf{a}$ and $\mathbf{b}$ Photographs show the surgical procedure of cutting the lesion. c Photograph shows the mass cutted off from the eyelid. $\mathbf{d}$ Postoperative photograph shows no recurrence 10 months after surgery 
Table 2 Demographics and macroscopic findings in patients with synthetic fiber granulomas

\begin{tabular}{|c|c|c|c|c|c|c|c|}
\hline Authors & Case & $\begin{array}{l}\text { Age } \\
\text { (years) }\end{array}$ & Gender & Duration & $\begin{array}{l}\text { Location } \\
\text { (conjunctival) }\end{array}$ & $\begin{array}{l}\text { Size } \\
(\mathrm{mm})\end{array}$ & Color \\
\hline \multirow[t]{5}{*}{ Weinberg JC et al. [1] } & 1 & 6 & Male & 2 months & Inferior fornix, OS & $10 \times 4 \times 2$ & Pink \\
\hline & 2 & 8 & Female & 6 months & Inferior fornix, OS & $7 \times 2.5$ & Green \\
\hline & 3 & 16 & Female & 6 weeks & Superior fornix, OD & $7 \times 5 \times 3$ & White, blue-black \\
\hline & 4 & 4 & Male & 2 months & Inferior fornix, OD & N/D & N/D \\
\hline & 5 & 17 & Female & Several months & Inferior fornix, OD & $4 \times 4$ & N/D \\
\hline Shields et al. [2] & 6 & 2.2 & Female & 3 months & Inferior fornix, OD & $7 \times 7 \times 5$ & Red-yellow \\
\hline $\begin{array}{l}\text { Arocker-Mettinger et al. } \\
\text { [9] }\end{array}$ & 7 & 2.6 & Male & Several weeks & Inferior fornix, OS & N/D & Yellow-green \\
\hline Resnick et al. [6] & 8 & 5 & Female & 2 weeks & Inferior fornix, OD & $4 \times 3$ & Yellow-green \\
\hline Offret et al. [11] & 9 & 6 & Female & N/D & Inferior fornix, OD & N/D & N/D \\
\hline Ferry et a.l [7] & 10 & 5 & Female & N/D & Inferior fornix, OS & $10 \times 10$ & Yellow-white \\
\hline Lueder et al. [12] & 11 & 4 & Female & 1 month & Inferior fornix, OS & $2 \times 1$ & White \\
\hline Yang et al. [8] & 12 & 13 & Female & $N / D$ & Inferior fornix, OS & $4 \times 3$ & Blue \\
\hline Enzenauer et al. [3] & 13 & 4.5 & Female & 10 months & Inferior fornix, OS & $15 \times 10$ & White \\
\hline \multirow[t]{2}{*}{ Schmack et al. [4] } & 14 & 7 & Female & 5 months & Inferior fornix, OD & $5 \times 4 \times 2$ & White-yellow \\
\hline & 15 & 2 & Female & 4 weeks & Inferior fornix, OD & $10 \times 4 \times 3$ & Brown \\
\hline \multirow[t]{2}{*}{ Farooq et al. [10] } & 16 & 2 & Female & 3 weeks & OS & N/D & - \\
\hline & 17 & 5 & Female & 2 days & Inferior fornix, OS & $7 \times 5$ & N/D \\
\hline Batta et al. [13] & 18 & 3 & Male & 2 weeks & Inferior fornix, OD & $10 \times 2 \times 3$ & Gray \\
\hline Aliakbar-Navahi et al. [14] & 19 & 6 & Female & 1 month & Inferior fornix, OD & $5 \times 5$ & Red \\
\hline Mak et al. [5] & 20 & 7 & Female & 1 month & Inferior fornix, OS & $3.5 \times 1.5$ & N/D \\
\hline
\end{tabular}

N/D No data available

diagnosis of SFCG. Schmack et al. reported that the differential diagnosis of synthetic fiber conjunctival granuloma should include ophthalmia nodosa (insect and plant hairs), ligneous conjunctivitis, chalazion, pyogenic granuloma, dermoid, papillary hyperplasia, atypical dermoids or dermolipoma, or neoplasms such as rhabdomyosarcoma and vascular tumors $[2,4,12]$ Many ophthalmologists may diagnose conjunctival masses as conjunctival dermoids because of their appearance. Although conjunctival dermoid presents as a mass with fine hairs adhering to the conjunctival fornix, the STR analysis could demonstrate that the inside hair is homologous with the mass, which is the primary difference between synthetic fiber conjunctival granuloma and conjunctival dermoid. The histopathologic and immunohistochemistry findings could also assist with correct diagnoses.

All of the microscopic examinations of our patients' specimens revealed similar results, except in 2 cases. The foreign bodies found in these cases had not been described in previous literature. We could not clearly identify the foreign bodies but noted that they were surrounded by granulomatous inflammatory reactions. We suspect they were synthetic fibers that were not previously identified so further investigations are needed.

Treatment of SFCG involves surgical excision of the foreign body and granuloma followed by topical corticosteroids. None of the granulomas recurred at a mean follow-up period of 12 months. In our study, all of the patients underwent surgical excision under surface anesthesia except for one patient who underwent general anesthesia. Surface anesthesia has a number of potential advantages such as minimal bleeding and discomfort. It is currently well established from a variety of studies that if the patient is young, anxious, or non-compliant and the lesion is present for a long period before being recognized or is deeply embedded, general anesthesia is often needed $[3,12]$.

However, this retrospective observational case series has a few inherent limitations. The data were collected over a 4-year period based on the pathologic database, entailing some incomplete specimen data information. Furthermore, the small size of the dataset also meant that it was not possible to demonstrate all-sided features of SFCG. Our preliminary data still needs to be verified and enriched by investigations with more patients.

\section{Conclusions}

The present study was designed for the further investigation of SFCG. In conclusion, the diagnosis of teddy bear granulomas can be challenging for ophthalmologists. SFCG may be more common than previously realized. As the number of accurate reports increases, these significant 
findings will help ophthalmologists develop a better understanding of this disease and improve awareness of these lesions. The diagnosis should be considered in any patient with a painless mass in the palpebral conjunctiva or conjunctival fornix, which are by far the most common locations. Definite diagnosis can be made via microscopic evaluation. The best treatment is surgical excision followed by topical corticosteroid eye drops, which is clinically proven to be effective. Avoiding potential primary sources of synthetic fibers should prevent the growth of conjunctival granuloma. Hence, it could conceivably be hypothesized that early diagnosis and active and effective treatment will be possible. This study's results can provide a clinical basis for prevention and treatment of this disease.

\section{Supplementary Information}

The online version contains supplementary material available at https://doi. org/10.1186/s12886-020-01717-1.

Additional file 1. Clinical photographs of 18 patients with synthetic fiber conjunctival granuloma (only for review)

\section{Abbreviation}

SFCG: Synthetic fiber conjunctival granuloma

\section{Acknowledgements}

Not applicable.

\section{Authors' contributions}

All authors contributed to drafting this work or revising it critically for important intellectual content and provided approval for it to be published. All authors are in agreement to be accountable for all aspects of the work in ensuring that questions related to the accuracy or integrity of any part of the work are appropriately investigated and resolved. All authors acquired the data. ZDZ, ZC, TYW and ZLZ analysed the data. ZDZ and QTP contributed to the conception and design of the work.

\section{Funding}

Ophthalmic data collection, statistical analysis and publication charges in the study were supported by research grants from Natural Science Foundation of Zhejiang Province, China (84119092G).

\section{Availability of data and materials}

The datasets used and/or analysed during the current study available from the corresponding author on reasonable request.

\section{Ethics approval and consent to participate}

The study was approved by the Ethics Committee of the Wenzhou Medical University Eye Hospital (approval number:2020-163-K-148), and written informed consent was obtained from all patients. For the participants under the age of 16 years old, the consent has been obtained from a parent or guardian.

\section{Consent for publication}

Not applicable.

\section{Competing interests}

The authors declare no conflict of interest.

\section{Author details}

${ }^{1}$ Wenzhou Medical University Eye Hospital, 270 Xueyuan Road, Wenzhou 325027, Zhejiang, China. ${ }^{2}$ Yantai Affiliated Hospital of Binzhou Medical University, Yantai, Shandong, China.
Received: 9 August 2020 Accepted: 5 November 2020

Published online: 16 November 2020

References

1. Weinberg JC, Eagle RC Jr, Font RL, Streeten BW, Hidayat A, Morris DA. Conjunctival synthetic fiber granuloma: a lesion that resembles conjunctivitis nodosa. Ophthalmology. 1984;91:867-72.

2. Shields JA, Augsburger JJ, Stechschulte J, Repka M. Synthetic fiber granuloma of the conjunctiva. Am J Ophthalmol. 1985;99:598-600.

3. Enzenauer RW, Speers WC. Teddy bear granuloma of the conjunctiva. J Pediatr Ophthalmol Strabismus. 2002:39:46-8.

4. Schmack I, Kang SJ, Grossniklaus HE, Lambert SR. Conjunctival granulomas caused by synthetic fibers: report of two cases and review of literature. J AAPOS. 2006;9:567-71

5. Mak ST, Lui YH, Li KK. Synthetic fibre granuloma of the conjunctiva. Hong Kong Med J. 2015;21:77-9.

6. Resnick SC, Schainker BA, Ortiz JM. Conjunctival synthetic and nonsynthetic fiber granulomas. Cornea. 1991;10:59-62.

7. Ferry AP. Synthetic fiber granuloma. Teddy bear' granuloma of the conjunctiva. Arch Ophthalmol. 1994;112:1339-41.

8. Yang YF, James CR. A conjunctival synthetic fibre granuloma in a child. Eye. 1996:10:143-5.

9. Arocker-Mettinger E, Haddad R, Grabner G. Bindehautgranulom durch synthetische Fasern. Klin Monatsbl Augenheilkd. 1987;189:479-81.

10. Farooq MK, Prause JU, Heegaard S. Synthetic fiber from a teddy bear causing keratitis and conjunctival granuloma: case report. BMC Ophthalmol. 2011;11:1372-5.

11. Offret $H$, Quillard J. Granuloma of the conjunctiva caused by synthetic fibers. J Fr Ophtalmol. 1992;15:308-10.

12. Lueder GT, Matsumoto B, Smith ME. Pathological case of the month. Synthetic fiber granuloma. Arch Ophthalmol. 1996;113:848-9.

13. Batta B, Robin A, George JL, Angioi K. "Teddy bear granuloma", a rare condition: a case report of a 3-year-old child. J Fr Ophtalmol. 2012;35:117_ 20.

14. Aliakbar-Navahi R, Roozitalab MH, Ashraf MJ, Hakimzadeh A. Synthetic fiber "Teddy Bear" conjunctival granuloma; a case report. J Ophthalmic Vis Res. 2015;10:342-44.

\section{Publisher's Note}

Springer Nature remains neutral with regard to jurisdictional claims in published maps and institutional affiliations.
Ready to submit your research? Choose BMC and benefit from:
- fast, convenient online submission
- thorough peer review by experienced researchers in your field
- rapid publication on acceptance
- support for research data, including large and complex data types
- gold Open Access which fosters wider collaboration and increased citations
- maximum visibility for your research: over $100 \mathrm{M}$ website views per year
At BMC, research is always in progress.
Learn more biomedcentral.com/submissions 